\title{
COLON
}

\section{Effect of a protein and energy dense n-3 fatty acid enriched oral supplement on loss of weight and lean tissue in cancer cachexia: a randomised double blind trial}

\author{
K C H Fearon, M F von Meyenfeldt, A G W Moses, R van Geenen, A Roy, D J Gouma, A Giacosa, \\ A Van Gossum, J Bauer, M D Barber, N K Aaronson, A C Voss, M J Tisdale
}

See end of article for authors' affiliations

Correspondence to:

Professor K C H Fearon,

Department of Clinical and Surgical Sciences

(Surgery), Royal Infirmary

of Edinburgh, 51 Little

France Crescent,

Edinburgh EHI 6 4SA, UK

k.fearon@ed.ac.uk

Accepted for publication 18 March 2003

\begin{abstract}
Aim: N-3 fatty acids, especially eicosapentaenoic acid (EPA), may possess anticachectic properties. This trial compared a protein and energy dense supplement enriched with n-3 fatty acids and antioxidants (experimental: E) with an isocaloric isonitrogenous control supplement (C) for their effects on weight, lean body mass (LBM), dietary intake, and quality of life in cachectic patients with advanced pancreatic cancer. Methods: A total of 200 patients $(95 \mathrm{E} ; 105 \mathrm{C}$ ) were randomised to consume two cans/day of the $\mathrm{E}$ or $\mathrm{C}$ supplement ( $480 \mathrm{ml}, 620 \mathrm{kcal}, 32 \mathrm{~g}$ protein $\pm 2.2 \mathrm{~g} \mathrm{EPA})$ for eight weeks in a multicentre, randomised, double blind trial.

Results: At enrolment, patients' mean rate of weight loss was $3.3 \mathrm{~kg} / \mathrm{month}$. Intake of the supplements (E or C) was below the recommended dose (2 cans/day) and averaged 1.4 cans/day. Over eight weeks, patients in both groups stopped losing weight ( $\Delta$ weight $\mathrm{E}:-0.25 \mathrm{~kg} / \mathrm{month}$ versus $\mathrm{C}:-0.37 \mathrm{~kg} / \mathrm{month}$; $p=0.74)$ and $L B M(\Delta L B M E:+0.27 \mathrm{~kg} /$ month versus $C:+0.12 \mathrm{~kg} /$ month; $p=0.88)$ to an equal degree (change from baseline $E$ and $C, p<0.001$ ). In view of evident non-compliance in both $E$ and $C$ groups, correlation analyses were undertaken to examine for potential dose-response relationships. $E$ patients demonstrated significant correlations between their supplement intake and weight gain $(r=0.50$, $p<0.001)$ and increase in $\operatorname{LBM}(r=0.33, p=0.036)$. Such correlations were not statistically significant in $\mathrm{C}$ patients. The relationship of supplement intake with change in LBM was significantly different between $\mathrm{E}$ and $C$ patients $(p=0.043)$. Increased plasma EPA levels in the $E$ group were associated with weight and $\operatorname{LBM}$ gain $(r=0.50, p<0.001 ; r=0.51, p=0.001)$. Weight gain was associated with improved quality of life $(p<0.01)$ only in the $E$ group.

Conclusion: Intention to treat group comparisons indicated that at the mean dose taken, enrichment with $\mathrm{n}-3$ fatty acids did not provide a therapeutic advantage and that both supplements were equally effective in arresting weight loss. Post hoc dose-response analysis suggests that if taken in sufficient quantity, only the $\mathrm{n}-3$ fatty acid enriched energy and protein dense supplement results in net gain of weight, lean tissue, and improved quality of life. Further trials are required to examine the potential role of $n-3$ enriched supplements in the treatment of cancer cachexia.
\end{abstract}

$\mathrm{T}$ he complex syndrome of cancer cachexia is a major contributor to the morbidity and mortality of patients with advanced malignancy. ${ }^{12}$ Causative factors include metabolic alterations that result in hypermetabolism and anorexia leading to reduced food intake. Previous studies using conventional nutritional support have suggested there is a partial block to the accretion of lean tissue in cancer patients. ${ }^{3}$ Moreover, oral supplementation trials have failed to show weight gain compared with controls. ${ }^{45}$ Such data would tend to confirm the view that although food intake needs to be increased in the cachectic cancer patient, gain in lean tissue mass is difficult to achieve unless the underlying metabolic abnormalities are corrected. The mediators responsible for these changes are thought to be both tumour and host derived and include proinflammatory cytokines, the neuroendocrine system, and certain tumour specific factors such as proteolysis inducing factor (PIF). ${ }^{67}$

Eicosapentaenoic acid (EPA), an n-3 fatty acid, has been shown to have antitumour and anticachectic effects in the murine MAC-16 colon adenocarcinoma model. ${ }^{8}$ In this model, the effects of EPA have been related to inhibition of PIF induced upregulation of key regulatory components of the ubiquitin-proteasome proteolytic pathway. ${ }^{9}$ Administration of n-3 fatty acid or high purity EPA capsules has been associated with weight stabilisation in weight losing patients with advanced pancreatic cancer. ${ }^{10}{ }^{11}$ These benefits may be related to the effect of EPA on PIF but might also be related to downregulation of proinflammatory cytokine production. ${ }^{12}{ }^{13}$ Whatever the mechanism, to improve functional ability and hence quality of life, patients need not only to become weight stable but to regain the lean tissue lost in the cachectic process. Additional protein and energy are required for lean tissue synthesis; hence the rationale for incorporating EPA as part of a high protein high energy oral supplement. Furthermore, including specific antioxidants may enhance the effect by protecting the unsaturated n-3 fatty acids in the supplement. ${ }^{14}$ In an open label trial, consumption of two cans per day of such an oral supplement resulted in a median weight gain of $1 \mathrm{~kg}$ at three weeks and $2 \mathrm{~kg}$ at seven weeks in weight losing patients with pancreatic cancer $(n=20)$. Approximately $95 \%$ of the weight gain was lean body mass (LBM). ${ }^{15}$

The aim of the present study was to compare the effect of the same n-3 fatty acid and antioxidant enriched supplement

Abbreviations: EPA, eicosapentaenoic acid; PIF, proteolysis inducing factor; LBM, lean body mass; TBW, total body water 
(experimental: E) with an isocaloric isonitrogenous supplement (control: C) on weight, body composition, dietary intake, and quality of life in weight losing pancreatic cancer patients. The hypothesis was that n-3 fatty acids would modulate metabolic abnormalities and thus promote anabolism in patients with cachexia. Addition of protein and energy would provide the elements necessary for the net gain of weight and lean tissue.

\section{PATIENTS AND METHODS Patients}

Patients with unresectable pancreatic cancer were selected specifically for this study as these patients usually experience severe progressive weight loss. Patients with histologically proven or a firm radiological or operative diagnosis of pancreatic cancer were included if they had lost more than $5 \%$ of their pre-illness stable weight over the previous six months, had a Karnofsky performance score of 60 or more, and had a life expectancy greater than two months. Patients were excluded if they had undergone surgery, endoscopic stenting, radiotherapy, or chemotherapy during the previous four weeks; had other active medical conditions (major gastrointestinal disease, chronic renal failure, uncontrolled diabetes, and human immunodeficiency virus); a body mass index greater than $30 \mathrm{~kg} / \mathrm{m}^{2}$; or received medication which could profoundly modulate metabolism or weight, in particular, the use of fish oil or n-3 fatty acid preparations exceeding $200 \mathrm{mg} /$ day EPA, or one capsule of fish oil/day within the previous 90 days. At the time of enrolment, no patient had gross ascites or oedema, jaundice, pyrexia, severe anaemia, or clinical or radiological evidence of infection. A small number $(n=8)$ were receiving long term low dose steroids for chronic benign conditions (for example, asthma). None was taking steroids at doses above that for physiological replacement. Pancreatic enzyme supplements were administered if patients had or developed clinical evidence of steatorrhoea. The ethics committees for human research of the participating centres approved the protocol, and written informed consent was obtained from all patients. Procedures followed were in accordance with International Committee for Harmonization, Good Clinical Practices and the Helsinki Declaration.

\section{Study design}

The study was an international, multicentre, randomised, double blind trial and was conducted between 27 January 1999 and 1 January 2001. Stratification was applied for the 12 participating centres and histological confirmation of pancreatic cancer. The 12 participating centres were: Royal Infirmary of Edinburgh, Edinburgh, UK; University Hospital of Maastricht, Maastricht, the Netherlands; Centre Hospilalier de l'Universite de Montreal (CHUM), Montreal, Canada; Academisch Medisch Centrum, Amsterdam, the Netherlands; Istituto Nazionale per la Ricerca sul Cancro, Genoa, Italy; Universite Libre de Bruxelles Erasme, Brussels, Belgium; The Wesley Hospital, Brisbane, Australia; Princess Alexandra Hospital, Brisbane, Australia; Manchester Royal Infirmary, Manchester, UK; Russells Hall Hospital, Dudley, UK; Hammersmith Hospital, London, UK; and the General Infirmary at Leeds, Leeds, UK. Patients were randomised at enrolment in permutation blocks of two using a sequential series of numbered sealed envelopes containing computer generated random assignments. A copy of the randomisation sequence was kept in a locked cabinet apart from the study personnel. Randomisation envelopes were opened by a third party who shipped the product directly to the patients' homes. Patients, investigators, and study personnel were blinded to the treatment group allocation. Study products were packaged identically and not distinguishable from each other. A sample size of 68 patients was calculated to detect a difference in body weight of $1.6 \mathrm{~kg}$ (that is, an effect size of 0.8 ) between groups with a significance level of 0.05 and a power of 0.9. Statistical power was based on changes in weight from the pilot study data. ${ }^{15}$ Sample size was inflated to 80 patients due to anticipating smaller effect size in other measures (that is, quality of life). Therefore, 200 patients were required to be enrolled in the study to obtain a minimum of 80 patients, based on an anticipated $60 \%$ attrition rate.

Patients were asked to consume two cans per day of either a specially designed n-3 fatty acid and antioxidant enriched oral supplement (E) or the identical supplement without n-3 fatty acids and enhanced antioxidants (C) for an eight week period. Compliance was evaluated using the supplement consumption records kept daily by patients and after the blind was broken by measurement of plasma phospholipid EPA levels.

Both oral supplements were provided by Ross Products Division, Abbott Laboratories (Columbus, Ohio, USA) and were ready to use, energy dense, high protein, low fat formulations intended to act as a supplement to the patient's usual diet. Each $237 \mathrm{ml}$ can provided $310 \mathrm{kcal}, 16 \mathrm{~g}$ protein, $6 \mathrm{~g}$ fat, with or without $1.1 \mathrm{~g}$ of the n-3 fatty acid EPA, and enriched antioxidants sufficient to protect the polyunsaturated fatty acids from peroxidation (2524 IU vitamin A, 75 IU vitamin $\mathrm{E}, 105 \mathrm{mg}$ vitamin $\mathrm{C}$, and $17.5 \mu \mathrm{g}$ selenium). The complete composition has been described by Barber and colleagues. ${ }^{15}$ Patients were assessed for weight, body composition, dietary intake, and quality of life at baseline, and at four and eight weeks.

\section{Weight and body composition}

At the initial assessment, height, pre-illness stable weight, and duration of weight loss were self reported. Patients were weighed without shoes and wearing light clothing on spring balance scales (Tanita Solar Powered Scale Model 1618, Tanita, Uxbridge, Middlesex, UK). The same scales were used for consecutive visits.

Body composition was assessed using a Xitron Hydra multiple frequency bioelectrical impedance analyser (Xitron Technologies, San Diego, California, USA), as described previously. ${ }^{16}$ Resistance was measured at $5 \mathrm{kHz}$ and $200 \mathrm{kHz}$. Total body water (TBW) was derived using equations validated in surgical patients. ${ }^{16}$ LBM was calculated from TBW assuming that lean tissue contains $73 \%$ water. ${ }^{17}$ Pre-illness LBM was estimated from pre-illness body weight using predictive equations based on height and weight for TBW. ${ }^{18}$

\section{Dietary intake}

Three day diet diaries completed prior to assessments at baseline (week 0), and weeks 4 and 8 were used to assess the patients' dietary intakes. Diet diaries have been shown to reflect usual dietary intake. ${ }^{19} 20$ One weekend day and two weekdays were used to account for potential day of the week effects on dietary intake. ${ }^{20}$ A dietitian instructed patients on how to record food and beverage intake. Mean total energy and macronutrient intakes were calculated using country specific computerised dietary analysis packages. Patients were also asked to record the number of cans of supplement, or parts thereof, consumed each day. Total dietary intake was calculated by adding oral supplement consumption to spontaneous food intake.

\section{Plasma fatty acid analysis}

Analysis of EPA in patients' plasma phospholipids before study commencement and at four and eight weeks was performed by gas chromatography, as described previously..$^{10}$ 
A plasma EPA level of $1.6 \%$ is approximately the 90th percentile in free living pancreatic cancer patients, ${ }^{15}{ }^{21}$ and this was used as the upper limit of the normal range.

\section{Quality of life assessment}

Quality of life was measured at baseline, and at four and eight weeks using two self administered questionnaires: (1) EuroQol EQ-5D, a generic quality of life measure that provides a single index score (EQ- $\left.5 \mathrm{D}_{\text {index }}\right)$ and the respondent's assessment of his or her overall health state (EQ$\left.5 \mathrm{D}_{\text {vas }}\right)^{22}$; and (2) the European Organization for Research and Treatment of Cancer (EORTC) QLQ-C30, a multidimensional cancer specific measure that includes a global health status and quality of life scale, function, and symptom scales. ${ }^{23}$ The physical performance and global health status components alone were used in the statistical analysis. Karnofsky performance score was also documented.

\section{Statistical analysis}

The primary analysis was conducted on an intent to treat basis, and therefore available data from all patients entered into the study were used. Study groups were assessed for comparability at study entry. For continuous variables, changes were calculated as week 4 minus baseline and week 8 minus baseline. Continuous variables were analysed using a two sample $t$ test or Wilcoxon rank sum test, as appropriate. Categorical variables were analysed using a $\chi^{2}$ test or Fisher's exact test, as appropriate. Post hoc within group analyses were conducted to examine changes from baseline to week 4 and 8 using the paired $t$ test or Wilcoxon signed rank test, as appropriate. Correlation product moment analyses were performed, within groups, on a subset of the data variables. The relationship of supplement consumption, plasma EPA, and dietary intake with the study end points was assessed for the two groups using analysis of covariance and also separately for the experimental and control groups using the Pearson correlation coefficient. The Wilcoxon signed rank test was used to examine whether there was a relationship between the amount of experimental product consumed and specific outcomes. Patient survival was estimated from the date of study enrolment by the Kaplan-Meier method. All results were considered to be statistically significant if the $p$ value was less than 0.05 .

\section{RESULTS}

A total of 200 weight losing patients (95E and 105C) with unresectable pancreatic cancer were enrolled and randomised in the study. Patient characteristics at enrolment and baseline are shown in table 1 . The two groups were comparable for all variables $(\mathrm{p}>0.05)$. However, there was a trend towards a greater proportion of stage IV disease patients in the experimental group (52\%) than in the control group $(41 \%)$. At baseline, patients had been losing approximately $3.3 \mathrm{~kg} /$ month $(2.2 \mathrm{~kg}$ of which was estimated to be LBM) and had lost $17 \%$ of their pre-illness stable weight. Approximately one third of patients in each group $(32 \% \mathrm{E}$, $28 \%$ C) were using pancreatic enzyme supplements for the treatment of steatorrhoea/malabsorption at the start of the study. Patients were well matched for Karnofsky performance score and quality of life characteristics (table 1). In general, the values reflect a debilitated older group of patients with significant impairment of physical function and global health status.

Fifteen patients withdrew between enrolment and baseline. Thus 185 patients ( $88 \mathrm{E}$ and $97 \mathrm{C}$ ) were assessed at baseline. Thereafter, 148 patients were assessed at four weeks (70E and 78C) and 110 at eight weeks (50E and 60C) (fig 1). The reasons for sample attrition between enrolment and the end of the eight week study period are also shown in fig 1. Both the experimental and control oral supplements were well tolerated. There were no significant differences in the number of patients who experienced adverse events or serious adverse events between the experimental and control groups. None of the serious adverse events were considered to be due to the oral supplements. Rather, the investigators concluded that they were due to disease progression.

\begin{tabular}{|c|c|c|}
\hline & $\begin{array}{l}\text { Experimental group } \\
(\mathrm{n}=95)\end{array}$ & $\begin{array}{l}\text { Control group } \\
(n=105)\end{array}$ \\
\hline \multicolumn{3}{|l|}{ Enrolment characteristics } \\
\hline Sex (M:F) & $54: 41$ & $56: 49$ \\
\hline Age (y) & $67(1)$ & 68 (1) \\
\hline Histological proof of diagnosis & $55(58 \%)$ & $61(58 \%)$ \\
\hline \multicolumn{3}{|l|}{ Stage of disease } \\
\hline ॥ & $31(33 \%)$ & 40 (39\%) \\
\hline III & $14(15 \%)$ & $21(20 \%)$ \\
\hline IV & $49(52 \%)$ & $42(41 \%)$ \\
\hline Usual weight (kg) & 72.7 (1.2) & $74.7(1.4)$ \\
\hline \multicolumn{3}{|l|}{ supplementation } \\
\hline Baseline characteristics (0 weeks) & Experimental & Control \\
\hline Weight at baseline $(\mathrm{kg})$ & $60.3(1.1)(n=88)$ & $61.4(1.2)(n=97)$ \\
\hline Duration of weight loss (weeks) & $26.0(2.1)(\mathrm{n}=88)$ & $25.3(2.0)(n=96)$ \\
\hline Rate of weight loss ( $\mathrm{kg} / 4$ weeks) & $2.9(0.2)(\mathrm{n}=88)$ & $3.2(0.3)(n=96)$ \\
\hline$\%$ weight loss from usual weight & $17.9(0.9)(\mathrm{n}=88)$ & $17.1(0.8)(n=97)$ \\
\hline Body mass index $\left(\mathrm{kg} / \mathrm{m}^{2}\right)$ & $21.8(0.4)(n=88)$ & $22.0(0.4)(n=97)$ \\
\hline Lean body mass $(\mathrm{kg})$ & $43.3(0.9)(n=80)$ & $43.4(0.9)(\mathrm{n}=91)$ \\
\hline Karnofsky performance score & $74.9(1.2)(n=88)$ & $73.9(1.0)(n=98)$ \\
\hline$E Q-5 D_{\text {index }}$ & $0.62(0.03)(n=86)$ & $0.62(0.03)(\mathrm{n}=91)$ \\
\hline$E Q-5 D_{\text {vas }}$ & $52.3(2.2)(n=87)$ & $57.2(1.9)(n=96)$ \\
\hline EORTC QLQ-C30 global HS & $48.8(2.2)(n=86)$ & $53.1(2.2)(n=95)$ \\
\hline EORTC QLQ-C30 physical function & $64.1(2.2)(n=87)$ & $67.7(2.3)(n=96)$ \\
\hline Meal intake (kcal/day) & $1504(54)(n=84)$ & $1613(51)(n=95)$ \\
\hline Meal intake (g protein/day) & $60(2)(n=84)$ & $63(2)(n=95)$ \\
\hline
\end{tabular}




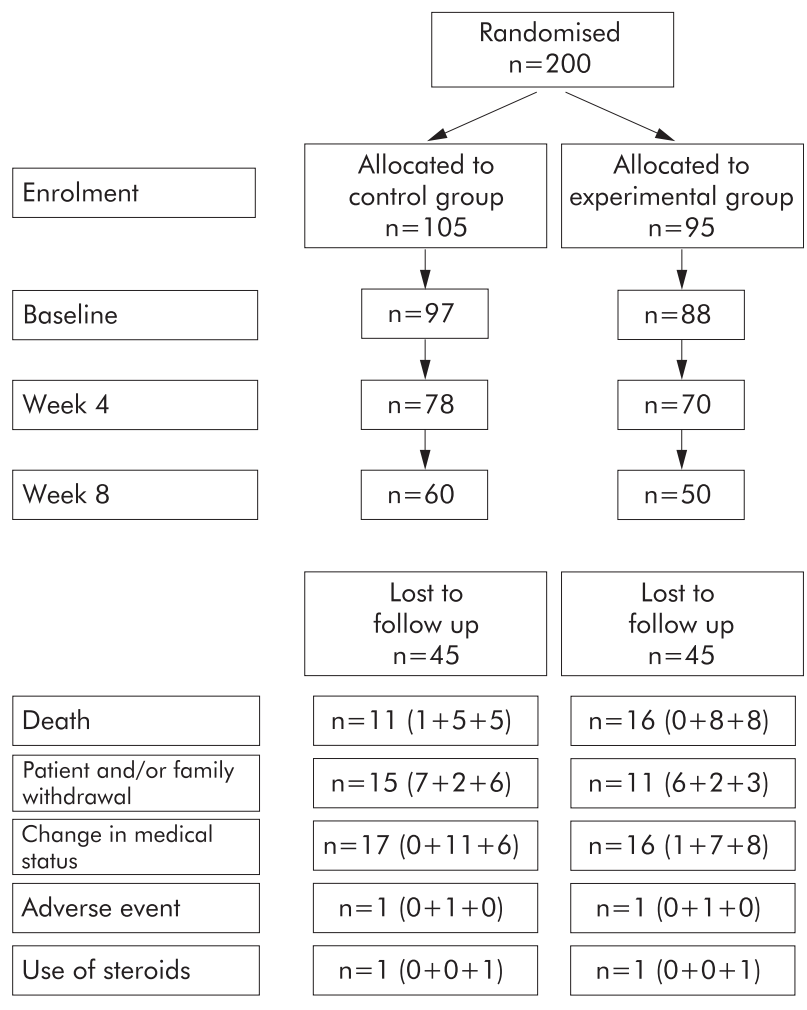

Figure 1 Patient disposition. Number of patients lost to follow up (enrolment to baseline+baseline to week $4+$ week 4 to week 8 ).

The recommended supplement dose was 2 cans/day. However, intake of the supplements (E or C) averaged 1.4 cans/day. Oral supplement consumption and dietary intake (completed by 100/110 patients at eight weeks) are shown in table 2. There was no significant difference between the groups for supplement intake $(p=0.63)$ or for change in meal $(p=0.24)$ or total dietary intake $(p=0.16)$ over the eight week period. However, there was a significant increase in total (meals plus supplement) dietary intake from baseline for those patients in the experimental group completing eight weeks (15 g protein/day $(\mathrm{p}<0.001)$ and $224 \mathrm{kcal} /$ day $(\mathrm{p}=0.001))$. In contrast, total protein intake increased significantly but there was only a trend towards an increase in total energy intake for those patients completing eight weeks in the control group ( $6 \mathrm{~g}$ protein/day $(\mathrm{p}=0.036)$ and $68 \mathrm{kcal} /$ day $(\mathrm{p}=0.098))$.

Based on plasma phospholipid EPA levels, there was evidence of deviation from protocol in both the control and experimental groups. There were patients in both groups with high levels of EPA at baseline (14\%), suggesting possible undisclosed prior supplementation with n-3 fatty acids. In addition, $18 \%$ of control patients had high EPA levels at weeks 4 and/or 8 . Conversely, 26\% of experimental patients had reported at least some intake of the experimental supplement but had little or no elevation of EPA (that is, $\leqslant 1.6 \%)$ in plasma at either week 4 or 8 .

Observed changes in weight and LBM after four and eight weeks of oral supplementation are shown in figs 2 and 3. Over the eight week study period, weight $(\Delta$ weight $\mathrm{E}$ : $-0.25 \mathrm{~kg} /$ month versus $\mathrm{C}$ : $-0.37 \mathrm{~kg} /$ month) and $\mathrm{LBM}$ ( $\Delta$ LBM E: $+0.27 \mathrm{~kg} /$ month versus C: $+0.12 \mathrm{~kg} / \mathrm{month}$ ) were stable and not significantly different between groups $(\mathrm{p}=0.74, \mathrm{p}=0.88$, respectively). When compared with rates of loss at baseline, there was a significant attenuation of weight and LBM loss in both study groups at four and eight weeks $(\mathrm{p}<0.001$ for all within group comparisons). There were no significant differences in prestudy rates of loss of weight or LBM between patients who did or did not complete the eight week study period. With respect to other indices over the trial period, there were no significant differences between groups in performance scores or any of the quality of life measures (data not shown).

In view of the relatively low mean levels of compliance, correlation analyses were undertaken to examine for potential dose-response relationships in either group (E or C) over the eight week study period. There was a significant positive correlation in the experimental group between daily supplement intake and increases in both body weight $(r=0.50$, $\mathrm{p}<0.001$ ) (fig 4A) and LBM ( $r=0.33, \mathrm{p}=0.036$ ) (fig 4C). In contrast, there were no such correlations in the control group (fig 4B, 4D). A comparison of the relationships between supplement intake and change in weight or LBM in the experimental group versus the control group suggested the correlations to be marginally different for weight $(p=0.053)$ and significantly different for lean body mass $(p=0.043)$. In the experimental group, maximal gain in weight and LBM was observed with an intake of 1.5-2 cans per day (fig 5). Moreover, there was a significant positive correlation between week 8 plasma EPA and increases in weight $(r=0.50 ; \mathrm{p}<0.001)$ and LBM $(r=0.51, \mathrm{p}=0.001)$ (fig 6) in the experimental group.

Although there were no significant differences in quality of life measures between the two groups, the intake of the experimental supplement correlated positively with quality of life as measured by EQ5D $\mathrm{D}_{\text {index }}(r=0.37, \mathrm{p}=0.01)$ while the intake of control supplement showed no such correlation $(r=0.04, \mathrm{p}=0.77)$. There was a trend suggesting these relationships to be significantly different $(\mathrm{p}=0.082)$. Weight gain in the experimental group correlated significantly with $\mathrm{EQ} \mathrm{D}_{\text {index }}(r=0.46, \mathrm{p}<0.001)$. There was no such statistically significant correlation $(\mathrm{p}=0.59)$ observed within the control group. Covariate analysis confirmed these relationships to be significantly different $(\mathrm{p}=0.038)$.

Table 2 Oral nutritional supplement intake and change in meal intake and total dietary intake for the experimental and control groups over the eight week study period

\begin{tabular}{lcc}
\hline & Experimental & Control \\
\hline Supplement intake (cans/day) & $1.44(0.1)(n=44)$ & $1.43(0.06)(n=56)^{\mathrm{a}}$ \\
Supplement intake (kcal/day) & $448(23)(n=44)$ & $444(19)(n=56)^{\mathrm{a}}$ \\
Supplement intake (g pro/day) & $23(1.2)(\mathrm{n}=44)$ & $23(1.0)(\mathrm{n}=56)^{\mathrm{a}}$ \\
Meal intake (kcal/day) & $-223(63)(\mathrm{n}=44)^{\mathrm{c}}$ & $-376(65)(\mathrm{n}=56)^{\mathrm{a}} \mathrm{c}$ \\
Meal intake (g protein/day) & $-8(3.2)(\mathrm{n}=44)^{\mathrm{b}}$ & $-17(3.2)(\mathrm{n}=56)^{\mathrm{a}} \mathrm{c}$ \\
Total intake (kcal/day) & $224(68)(\mathrm{n}=44)^{\mathrm{c}}$ & $68(64)(\mathrm{n}=56)^{\mathrm{a} d}$ \\
Total intake (g protein/day) & $15(3.5)(\mathrm{d}=44)^{\mathrm{c}}$ & $6(3.3)(\mathrm{n}=56)^{\mathrm{a}} \mathrm{b}$ \\
\hline
\end{tabular}

aExperimental versus control, $\mathrm{p}=\mathrm{NS}$

Change from baseline to 8 weeks: ${ }^{b} p \leqslant 0.05, c p \leqslant 0.001$, dNS

Values are mean (SEM). 


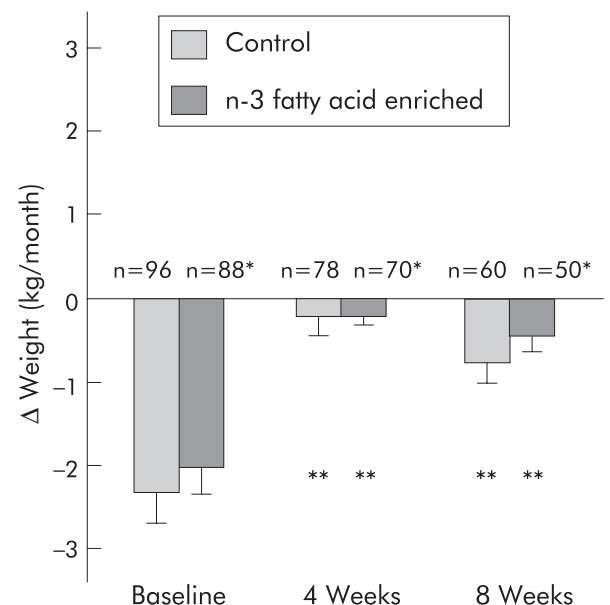

Figure 2 Effect of protein and calorie dense oral supplements, with or without $n-3$ fatty acids, on weight change in patients with pancreatic cancer cachexia. ${ }^{*} \mathrm{NS}(\mathrm{p}=0.49)$ at baseline, 0.95 at four weeks, and 0.74 at eight weeks between groups; ${ }^{* *} p<0.001$ within group comparisons to baseline.

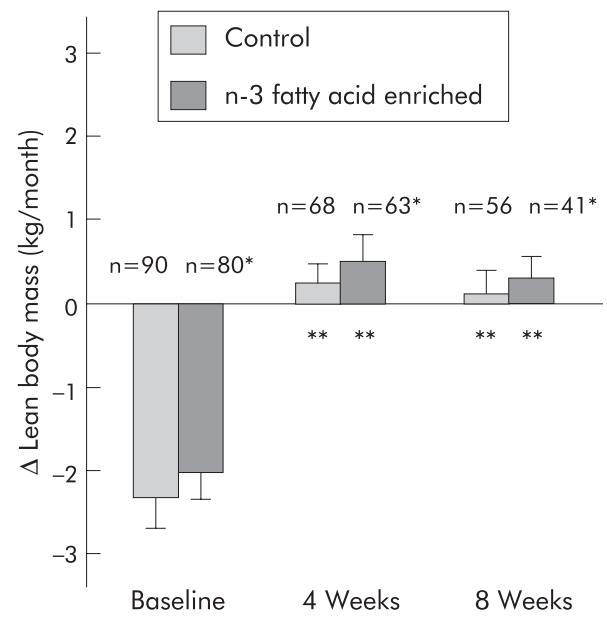

Figure 3 Effect of protein and calorie dense oral supplements, with or without $n-3$ fattly acids, on change in lean body mass in patients with pancreatic cancer cachexia. ${ }^{*} N S(p=0.85)$ at baseline, 0.95 at four weeks, and 0.88 at eight weeks between groups; ${ }^{* *} p<0.001$ within group comparisons to baseline.

Median duration of survival from study enrolment for all patients was 130 days and there was no significant difference between the treatment groups (E: 142 (6-587) days; C: 128 (8-626) days (median (range)).

\section{DISCUSSION}

The present study has demonstrated no clear advantage at the mean dose taken ( 1.4 cans/day) from enrichment of specialised protein and energy dense oral supplements with n-3 fatty acids in the treatment of patients with advanced cancer cachexia. At baseline, patients had lost, on average, $17 \%$ of their pre-illness weight and were actively losing weight at a rate of approximately $3.3 \mathrm{~kg} /$ month. Previous studies of untreated patients have demonstrated a linear pattern of continuous weight loss until near the time of death in patients with unresectable pancreatic cancer. ${ }^{24}$ The present study demonstrated that administration of specialised protein and energy dense oral supplements (whether or not enriched with n-3 fatty acids and antioxidants) was associated with weight stabilisation which would tend to suggest a net benefit from the use of such supplements in this particular group of patients. However, due to the advanced nature of their disease only $75 \%$ of patients reached the four week end point and $55 \%$ of patients the eight week end point. It could therefore be argued that the most severely cachectic patients had either died or withdrawn by week 8 thus leaving patients who were more weight stable. However, the baseline rate of weight loss was similar in patients who did or did not reach week 8 . This suggests that the observed attenuation of cachexia was a genuine effect and not due to selective attrition from either group.

At baseline, intakes of energy (1500-1600 kcal/day) and protein (60-65 g/day) were insufficient to allow patients to maintain body weight. The increased basal requirements of cachectic cancer patients may have contributed to such an imbalance. During the study, patients in both groups consumed on average 1.4 cans of oral supplement per day (equivalent to $420 \mathrm{kcal}$ and $21 \mathrm{~g}$ protein/day). Although spontaneous meal intake was partially reduced, the net gain in total energy and protein intake appeared sufficient to allow the patients in both groups to achieve overall weight stability (fig 2). Previous trials of dietary advice and conventional $(1 \mathrm{kcal} / \mathrm{ml})$ oral supplements in cancer patients undergoing outpatient chemotherapy have suggested no advantage compared with no dietary intervention. ${ }^{45}$ Overall, patients remained weight stable. However, in the latter studies patients were at an earlier stage in disease, were undergoing active anticancer treatment, and had not sustained the degree of weight loss observed in the present study. Clearly, however, in the absence of an untreated control group in the present trial it is not possible to assess definitely the efficacy of energy and protein dense oral supplements in advanced cancer cachexia.

The experimental supplement used in this study was designed to deliver a pharmacological dose of n-3 fatty acids within a nutrient matrix to provide extra protein and energy and allow net deposition of lean tissue. However, by incorporating the EPA in a nutritional supplement, the dose of EPA was then linked to overall supplement intake. Previous studies in cachectic pancreatic cancer patients suggested that EPA alone at a dose of $2 \mathrm{~g}$ /day was associated with weight stability $^{10}$ and that when incorporated in a nutrient matrix as used in the present study, a dose of $2.1 \mathrm{~g}$ /day (from consumption of 1.9 cans/day) was associated with net gain of lean body mass. ${ }^{15}$ Average can consumption in the present trial was 1.4 cans/day (containing $1.5 \mathrm{~g}$ EPA). Although arrest of further loss of both weight and lean tissue was observed, at this mean level of intake there was no net gain of lean body mass and no advantage for the supplement enriched with n-3 fatty acids and antioxidants when compared with the control supplement. It therefore remains to be tested whether if compliance can be improved (such that a net dosed EPA of $2 \mathrm{~g} /$ day is administered) there would be an advantage for n-3 enriched energy and protein dense oral supplements in terms of achieving net anabolism.

One explanation for the difference in compliance between the pilot study ${ }^{15}$ (average intake 1.9 cans/day) and the present randomised controlled trial (average 1.4 cans/day) would be different levels of patient motivation for supplement consumption based on the patient's perception of potential benefit in the context of a single arm study versus a randomised trial. Further studies focused on methods of optimising compliance (for example, patient information sheets) both within and outwith the context of randomised studies would be useful. Moreover, although compliance could be checked for the experimental supplement using plasma EPA levels, it would be useful for further studies to 
$\triangle$ Control

n-3 fatty acid enriched
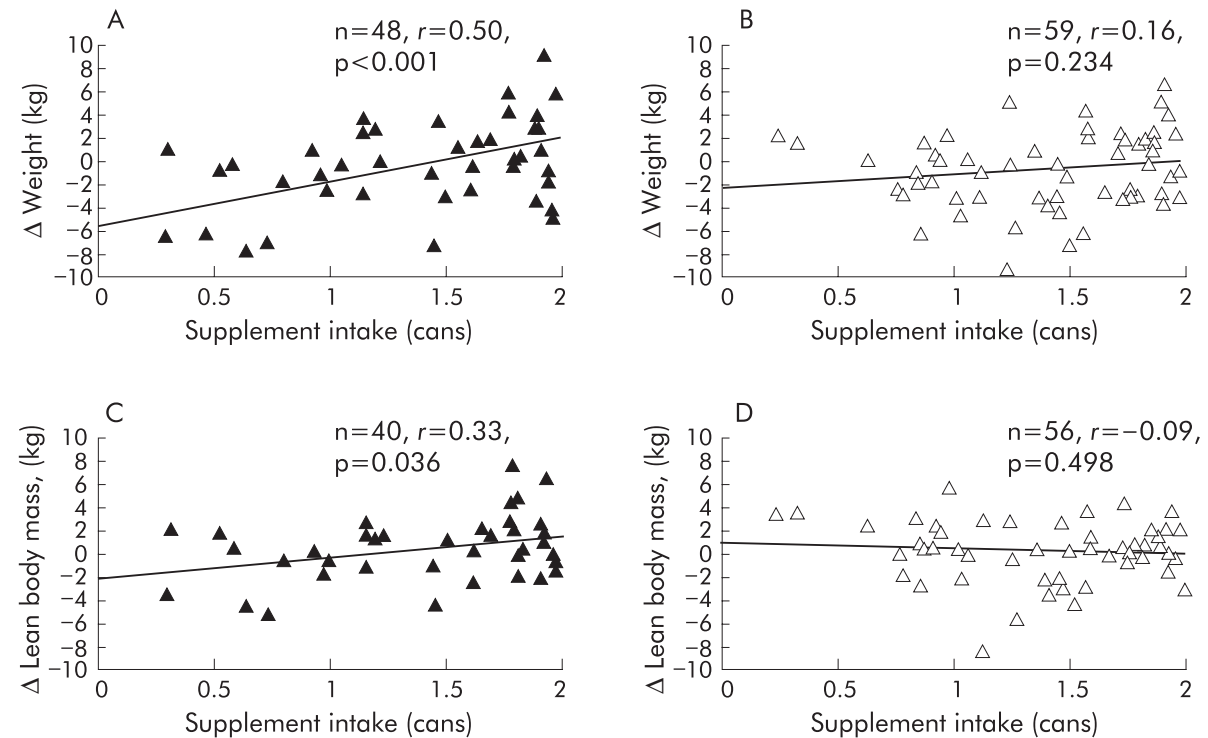

Figure 4 Relationship between oral supplement intake, with or without n-3 fatty acids, and weight (A, B) or lean body mass (C, D) of patients with pancreatic cancer cachexia after eight weeks of supplementation.

have a tracer (for example, deuterated water) in both the control and experimental oral supplements.

In the present study, patients had been stratified for centre and histological proof of diagnosis, but not for stage of disease. Baseline characteristics revealed that there were more stage IV patients randomised to the experimental group. Although not statistically significant, this could have influenced the results observed with group comparisons as patients with more advanced disease might be less able to take in normal food, and consume and respond to the intervention. In addition, the combined effect of some patients in both groups failing to declare n-3 fatty acid supplement use at baseline and some patients in the control group supplementing themselves with an alternative source of $n-3$ fatty acids during the trial may have further dampened any treatment differences that could have been observed between groups.

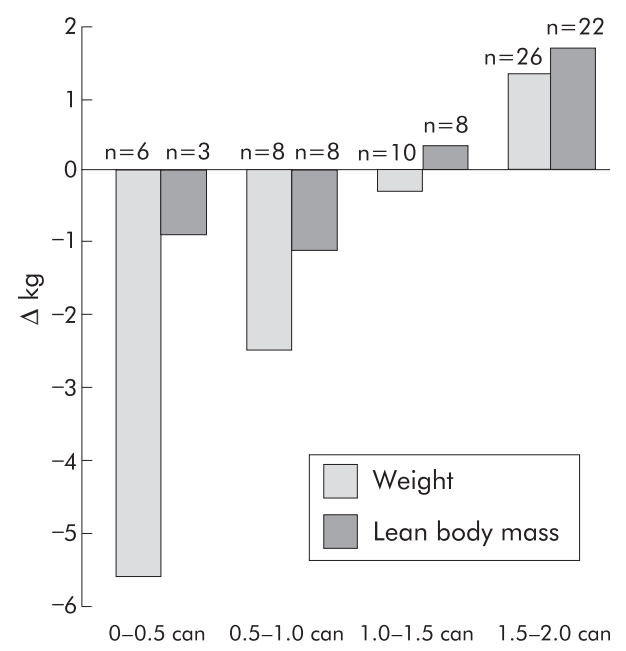

Figure 5 Effect of intake of protein and calorie dense oral supplement with n-3 fatty acids on change in weight and lean body mass at eight weeks in patients with pancreatic cancer cachexia.
In order to test whether there was a dose-effect relationship within the present study, a post hoc series of correlation analyses based on the ITT population was undertaken. These analyses demonstrated a significant positive correlation between intake of the supplement and gain in either body weight or LBM in the group receiving the experimental product (fig 4A, C). There was however no such relationship in the control group (fig 4B, D). Moreover, the relationship between supplement intake and change in LBM was significantly different between the experimental and control groups. A further observation supporting a dose-response relationship in the present study is that in those randomised to the experimental group, there was a significant positive correlation between week 8 plasma phospholipid EPA levels and an increase in body weight. Plasma phospholipid EPA levels also correlated strongly with changes in LBM (fig 6). Clearly, however, not all the change in LBM can be ascribed to changes in plasma EPA levels. Other modulating factors may include changes in the level of intake of other nutrients, changes in the level of physical activity of the patients, or genetically determined variation in the response to EPA. ${ }^{25}$

The aim of nutritional and metabolic support in cancer cachexia is not only to restore normal body composition but also to improve function and quality of life. Previous studies using the appetite stimulant medroxyprogesterone acetate

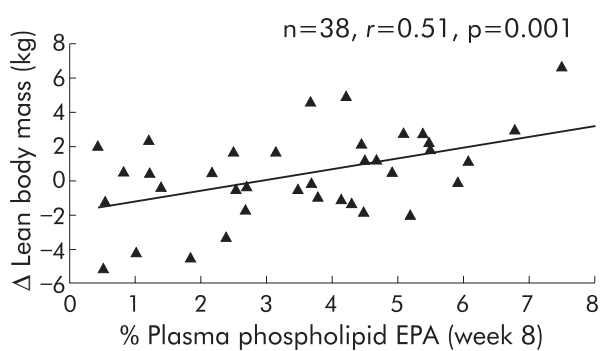

Figure 6 Relationship between plasma phospholipid eicosapentaenoic acid (EPA) levels and change in lean body mass at eight weeks in patients consuming the protein and calorie dense oral supplement with n-3 fatty acids. 
have demonstrated significant attenuation of weight loss in cachectic cancer patients. ${ }^{26}$ However, this did not translate into an improved quality of life (as assessed by the EORTC QLQ C-30). One explanation was that the main tissue preserved was fat rather than lean body mass. In the present study, LBM of patients who took the experimental supplement at the recommended dose (1.5-2 cans/day) increased (fig 5) and the intake of the experimental supplement was correlated positively with improved LBM and EQ- $5 D_{\text {index }}$. This potential relationship between LBM and quality of life is worthy of further study in patients with cancer cachexia.

Previous studies both in vitro and in vivo have suggested that n-3 fatty acids may have potential as antineoplastic therapy. Tumour response was not evaluated in the present study. However, there was no difference in the survival duration between control and experimental arms. The median survival of all patients from the time of enrolment was 130 days which is similar to that reported in recent randomised trials of chemotherapy or novel antineoplastic agents. ${ }^{27} 28$

In summary, due to a variety of compliance issues, the present trial failed to address the hypothesis developed from the pilot data. ${ }^{15}$ Further development of nutraceutical trial design is required to overcome these issues and address the potential efficacy of n-3 fatty acid enrichment of oral supplements in cancer cachexia. The issue of whether energy and protein dense oral supplements are of specific value is also worthy of further evaluation.

\section{ACKNOWLEDGMENTS}

We thank the patients and their care givers for their commitment to the study; the principal investigators, co-investigators, and study coordinators at the participating centres for their dedication and enthusiasm.

Abbott Laboratories, Chicago, IL, USA, J Boorman, S Coles, G Comer, J Edington, A Germinario, M Kappert, W Lam, M Mehran, L Ralph, L Tran; Academisch Medisch Centrum, Amsterdam, the Netherlands, T Van Heek, H VerMeulen, J Haver; Aston University, Birmingham, UK, P Sanders; Centre Hospilalier de l'Universite de Montreal (CHUM), Montreal, Canada, A Anderson, Y Caussignac, J Dorais, M Dube, J Gagnon, M Gehami, G Ghattas; Hammersmith Hospital, London, UK, G Frost, L Torgius; Istituto Nazionale per la Ricerca sul Cancro, Genoa, Italy, R Andreatta, M Ferro, F Frascio; Kendle, Sydney, Australia, T Johnson; Manchester Royal Infirmary, Manchester, UK, S Burden, K Ward; Princess Alexandra Hospital, Brisbane, Australia, D Wall; Royal Infirmary of Edinburgh, Edinburgh, UK, K Yuill; Russells Hall Hospital, Dudley, UK, P DeelSmith, J Gadd, A Fairhurst; The General Infirmary at Leeds, Leeds, UK, J McMahon; The Wesley Hospital, Brisbane, Australia; Universite Libre de Bruxelles Erasme, Brussels, Belgium, R Eskanazi, A Ghilain, G Phillipe, N Severs, S Vereecken; University of Sherbrooke, Sherbrooke (Quebec), Canada, H Payette.

\author{
Authors' affiliations \\ K C H Fearon, A G W Moses, M D Barber, Royal Infirmary of Edinburgh, \\ Edinburgh, UK \\ M F von Meyenfeldt, University Hospital of Maastricht, Maastricht, the \\ Netherlands \\ R van Geenen, D J Gouma, Academisch Medisch Centrum, Amsterdam, \\ the Netherlands \\ A Roy, Centre Hospitalier de I'University de Montreal, Montreal, \\ Canada \\ A Giacosa, Istituto Nazionale per la Ricerca sul Cancro, Genoa, Italy \\ A Van Gossum, Universite de Bruxelles Erasme, Brussels, Belgium \\ J Bauer, The Wesley Hospital, Brisbane, Australia \\ N K Aaronson, Antonie van Leeuwen Hoek Ziekenhuis, Amsterdam, the \\ Netherlands \\ A C Voss, Ross Products Division, Abbott Laboratories, Columbus, Ohio, \\ USA \\ M J Tisdale, Aston University, Birmingham, UK
}

Conflict of interest: A C Voss is an employee of Ross Products Division, Abbott Laboratories.

\section{APPENDIX}

\section{Contributors}

The trial concept was developed by KCH Fearon, MF von Meyenfeldt, AC Voss, MD Barber, and MJ Tisdale. The protocol was written by KCH Fearon and AC Voss. The trial was supervised by KCH Fearon, MF von Meyenfeldt, AC Voss, A Roy, DJ Gouma, A Giacosa, A van Gossum, and J Bauer. AGW Moses and R van Geenen did the majority of the clinical assessments. Quality of life assessments were interpreted by NK Aaronson. The final analysis was done by $\mathrm{KCH}$ Fearon, M von Meyenfeldt, and AC Voss. The paper was written by KCH Fearon, M von Meyenfeldt, and AC Voss. All authors contributed to the interpretation of the data, reviewed the paper, and approved the final version. Support was provided by Abbott Laboratories, Chicago, IL, USA.

\section{Cancer Cachexia Study Group}

The following additional physicians, study coordinators, clinical research associates, analytical scientists, dieticians, and statisticians participated in the Cancer Cachexia Study Group:

Academisch Medisch Centrum, Amsterdam, The Netherlands, D Gouma, R van Geenen; Antonie van Leeuwen Hoek Ziekenhuis, Amsterdam, the Netherlands, N Aaronson; Aston University, Birmingham, UK, M Tisdale; Centre for Health Economics, York, UK, P Kind; Centre Hospilalier de l'Universite de Montreal (CHUM), Montreal, Canada, A Roy; Hammersmith Hospital, London, UK, P Price; Istituto Nazionale per la Ricerca sul Cancro, Genoa, Italy, A Giacosa; Manchester Royal Infirmary, Manchester, UK, A Makin, A Siriwardena; Pennsylvania State University, USA, B Rolls; Princess Alexandra Hospital, Brisbane, Australia, S Ash, W Davidson; Queensland University of Technology, S Capra; Ross Products Division, Abbott Laboratories, Columbus, OH, USA, D Ataya, M Ferguson, W MacLean, K Mayer, K Ried, A Voss, A Wennberg; Royal Infirmary of Edinburgh, Edinburgh, UK, K Fearon, M Barber, A Moses, R Richardson, J Ross; Russells Hall Hospital, Dudley, UK, B Jones; Scottish Universities Environmental Research Centre, Glasgow, UK, $\mathrm{T}$ Preston; The General Infirmary at Leeds, Leeds, UK, M McMahon, M Larvin; The Wesley Hospital, Brisbane, Australia, J Bauer, I Martin; University Hospital of Maastricht, Maastricht, the Netherlands, M von Meyenfeldt, J Maessen; Universite Libre de Bruxelles Erasme, Brussels, Belgium, A van Gossum.

\section{REFERENCES}

1 Inagaki J, Rodriguez V, Bodey GP. Causes of death in cancer patients. Cancer 1974:33:568-73

2 DeWys WD, Begg C, Lavin PT, et al. Prognostic effect of weight loss prior to chemotherapy in cancer patients. Am J Med 1980;69:491-7.

3 Nixon DW, Lawson DH, Kutner M, et al. Hyperalimentation of the cancer patient with protein-calorie undernutrition. Cancer Res 1981;41:2038-45.

4 Evans WK, Nixon DW, Daly JM, et al. A randomised trial of oral nutritional support versus ad lib nutritional intake during chemotherapy for advanced colorectal and non-small-cell lung cancer. J Clin Oncol 1987;5:113-24.

5 Ovesen L, Allingstrup L, Hannibal J, et al. Effect of dietary counseling on food intake, body weight, response rate, survival, and quality of life in cancer patients undergoing chemotherapy: A prospective, randomised study. J Clin Oncol 1993;11:2043-9.

6 Fearon KCH, Barber MD, Moses AGW. The Cancer Cachexia Syndrome. Surg Oncol Clin N Am 2001; 10:109-26.

7 Todorov P, Cariuk P, McDevitt T, et al. Characteristics of a cancer cachexia factor. Nature 1996;379:739-74.

8 Beck SA, Smith KL, Tisdale MJ. Anticachectic and antitumour effect of eicosapentaenoic acid and its effect on protein turnover. Cancer Res 1991;51:6089-93.

9 Whitehouse AS, Smith HJ, Drake JL, et al. Mechanism of attenuation of skeletal muscle protein catabolism in cancer cachexia by eicosapentaenoic acid. Cancer Res 2001;36:177-84.

10 Wigmore SJ, Ross JA, Falconer JS, et al. The effect of polyunsaturated fatty acids on the progress of cachexia in patients with pancreatic cancer. Nutrition 1996;12(suppl):27-30.

11 Wigmore SJ, Barber MD, Ross JA, et al. Effect of oral eicosapentanoic acid on weight loss in patients with pancreatic cancer. Nutr Cancer 2000;36:177-84. 
12 Endres S, Ghorbani R, Kelley VE, et al. The effect of dietary supplementation with $n-3$ polyunsaturated fatty acids on the synthesis of interleukin- 1 and tumor necrosis factor by mononuclear cells. N Engl J Med 1989;320:265-71.

13 Wigmore SJ, Fearon $\mathrm{KCH}$, Maingay JP, et al. Down-regulation of the acutephase response in patients with pancreatic cancer cachexia receiving oral phase response in patients with pancreatic cancer cachexia receiving oral 1997;92:215-21.

14 Gogos CA, Ginopoulos P, Salsa B, et al. Dietary omega-3 polyunsaturated fatty acids plus vitamin $E$ restore immunodeficiency and prolong survival for severely ill patients with generalized malignancy. A randomised controlled trial. Cancer 1998;82:395-402.

15 Barber MD, Ross JA, Voss AC, et al. The effect of an oral nutritional supplement enriched with fish oil on weight-loss in patients with pancreatic cancer. Br J Cancer 1999:81:80-6.

16 Hannan WJ, Cowen SJ, Plester CE, et al. Comparison of bioimpedance spectroscopy and multi-frequency bioimpedance analysis for the assessment of extracellular and total body water in surgical patients. Clin Sci 1995:89:651-8.

17 Shizgal HM. Validation of the measurement of body composition from whole body bioelectric impedance. Infusionstherapie 1990;17(suppl 3):67-74.

18 Hume R, Weyers E. Relationship between total body water and surface area in normal and obese subjects. J Clin Pathol 1971;24:234-8.

19 Bingham S, Wiggins HS, Englyst $\mathrm{H}$, et al. Methods and validity of dietary assessments in four Scandinavian populations. Nutr Cancer 1982;4:23-33.

20 Gibson R. Principles of nutritional assessment. Oxford: Oxford University Press, 1990.
21 Zuijdgeest-Van Leeuwen SD, van der Heijden MS, Rietveld T, et al. Fatty acid composition of plasma lipids in patients with pancreatic, lung and oesophageal cancer in comparison with health subjects. Clin Nutr 2002;21:255-60

22 Kind P. EuroQol EQ-5D user guide. York: Centre for Health Economics, University of York, 1998.

23 Aaronson NK, Ahmedzai S, Bergman B, et al. The European Organization for Research and Treatment of Cancer QLQ-C30: A quality-of-life instrument for use in international clinical trials in oncology. J Natl Cancer Inst 1993:85:365-76.

24 Wigmore SJ, Plester CE, Richardson RA, et al. Changes in nutritional status associated with unresectable pancreatic cancer. Br J Surg 1997;75:106-9.

25 Grimble RF, Howell WM, O'Reilly G, et al. The ability of fish oil to suppress tumor necrosis factor alpha production by peripheral blood mononuclear cells in healthy men is associated with polymorphisms in genes that influence tumor necrosis factor alpha production. Am J Clin Nutr 2002;76:454-9.

26 Simons JP, Aaronson NK, Vansteeenkiste JF, et al. Effects of medroxyprogesterone acetate on appetite, weight, and quality of life in advanced-stage non-hormone-sensitive cancer: a placebo-controlled multicenter study. J Clin Oncol 1996;14:1077-84.

27 Johnson CD, Puntis M, Davidson N, et al. Randomized, dose-finding phase III study of lithium gamolenate in patients with advanced pancreatic adenocarcinoma. Br J Surg 2001;88:662-8.

28 Bramhall SR, Rosemurgy A, Brown PD, et al. Marimastat as first-line therapy for patients with unresectable pancreatic cancer: A randomized trial. J Clin Oncol 2001; 19:3447-55

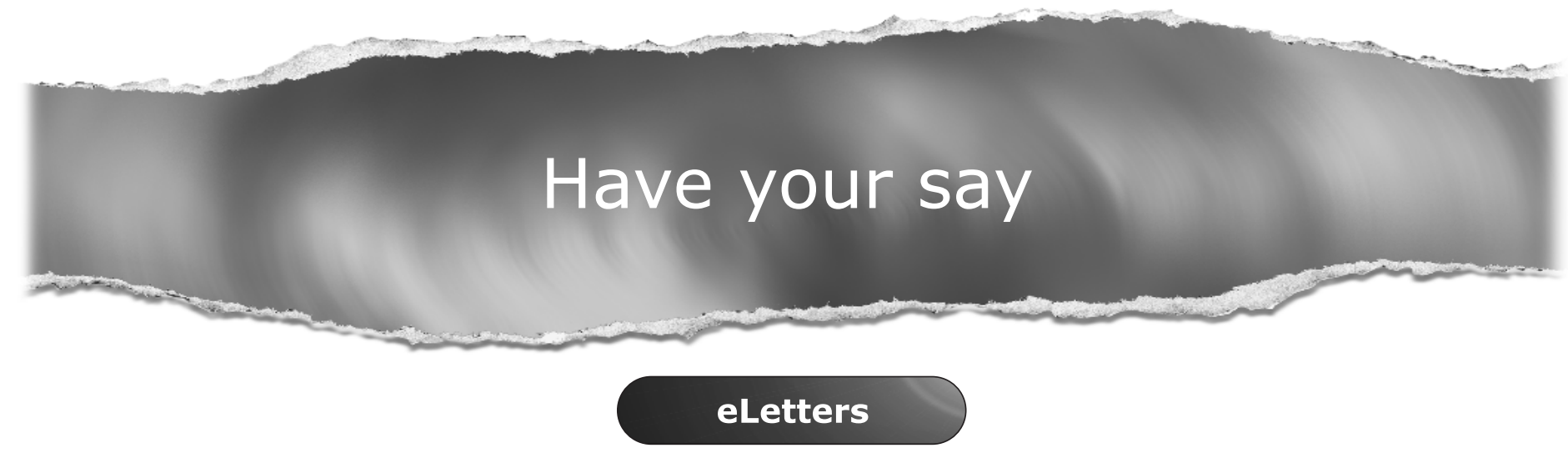

If you wish to comment on any article published in Gut you can send an eletter using the eletters link at the beginning of each article. Your response will be posted on Gut online within a few days of receipt (subject to editorial screening).

\section{www.gutjnl.com}

